\title{
Eco Concrete Characterization Using Steel Slag and Ground Granulated Blast Furnace Slag as Partial Replacement of Sand and Cement Respectively
}

\author{
Mekides Damena ${ }^{1}$, Shanmuga Vadivu ${ }^{2}$ \\ ${ }^{1}$ Construction Technology and Management, College of Architecture and Civil Engineering, Addis Ababa Science and Technology \\ University, Addis Ababa, Ethiopia \\ ${ }^{2}$ Department of Civil Engineering College of Architecture and Civil Engineering Addis Ababa Science and Technology University, Addis \\ Ababa, Ethiopia
}

\section{Email address:}

Mekdes.sup@gmail.com (M. Damena),mekides.damena@aastu.edu.et(M. Damena),vadivu72@gmail.com (S. Vadivu), Shanmugavadivu.marimuthu@aastu.edu.et (S. Vadivu)

\section{To cite this article:}

Mekides Damena, Shanmuga Vadivu. Eco Concrete Characterization Using Steel Slag and Ground Granulated Blast Furnace Slag as Partial Replacement of Sand and Cement Respectively. Landscape Architecture and Regional Planning. Vol. 5, No. 4, 2020, pp. 61-66. doi: $10.11648 /$ j.larp.20200504.11

Received: July 22, 2020; Accepted: August 4, 2020; Published: November 19, 2020

\begin{abstract}
The waste products of the factory mainly steel slag and GGBFS (ground granulated blast furnace slag) are used and recycled to gain concrete of different requirements related to strength and durability. In this research, it is intended to examine the impact of ground granulated blast furnace slag and steel slag replacement for cement and fine aggregate respectively. Both materials are taken from a factory of reinforcement bars which is located around Akaki kality sub-city, known as Akaki steel factory. The research additionally addresses X-ray diffraction (XRD), Scanning electron microscope techniques (SEM), and chemical composition of major oxides and minor oxides of the blast furnace slag. The main objective of this research targets in investigating an experimental aspect of replacing by-products of steel slag and ground granulated blast furnace slag partially on concrete production. It addresses the issue of a more expedite and urgent issue of our globalized world, climate change by replacing part of the concrete with these waste products. The followings are the main steps to carry out the researchAnalysis of properties of materials used as steel slag and ground granulated blast furnace slag. Blast furnace slag and steel slag mixed concrete mix design for partial substitution of cement and fine aggregate respectively. Find out the optimum replacement level of steel slag and that of ground granulated blast furnace slag in concrete. The thesis puts forward an experimental based analysis to determine the extent to which the industrial waste materials play a role in partial substitution of fine aggregate and cement in the preparation of concrete. From the experiments demonstrated flexural, tensile, and compressive strength of concrete is higher when GGBFS is replaced up to $5 \%$ of the cement and that of steel slag up to $30 \%$ of the sand.
\end{abstract}

Keywords: Steel Slag, Compressive Strength, Flexural Strength, Split Tensile Strength, Ground Granulated Blast Furnace Slag, XRD, SEM

\section{Introduction}

The overflow demand for materials by the building industry cannot be fully met by natural resources or traditional materials. Hence, there is a need to develop potential alternative materials to solve the increasing demands of building construction. The response to this issue can be found in the reuse of waste materials. The bi-products from industries are slag, rice husk ash, bagasse, fly ash, cement dust, brick dusk, blast furnace slag, sludge, glass, tires, sandpaper, silica fume, etc.

The above-listed waste materials represent a major problem for the environment because the dust and fine particles spread in the atmosphere which causes air pollution and leaching toxic chemicals like lead, cobalt, etc. also when they are dumped in landfills, quarries, rivers or oceans they 
cause serious damage on the water in which animals and humans can consume it and lead to a health problem.

The potential use of SS and GBFS from steel manufacturers as raw materials would benefit the sustainable development of the steel industry, as it would consume solid waste, save natural resources, and reduce material cost. The utilization of industrial waste materials in concrete compensates for the lack of natural resources, solving the disposal problem of waste, and finding an alternative technique to safeguard nature.

This paper investigates industrial wastes of steel slag and blast furnace slag and several experiments have been conducted using different physical and mechanical properties of this industrial waste as a partial replacement of fine aggregate and cement respectively.

\section{The objective of the Study}

\section{General objective}

To investigate the properties of concrete on partial replacement of cement and fine aggregate by industrial waste products of blast furnace slag and steel slag.

Specific objective

1) To investigate the properties of blast furnace slag and steel slag to know whether or not they can fulfill the properties of cement and sand.

2) To investigate the compressive, tensile, and flexural strength of concrete using steel slag as fine aggregate and blast furnace slag as cement.

3) To find out the optimum replacement level of steel slag and ground granulated blast furnace slag

\section{Literature Review}

This study investigates the use of SS and GBFS as the major raw materials in the preparation of concrete. GBFS powder, cement clinker are used as the binder; SS is used as fine aggregates. Physical properties and compressive strength development of the prepared concrete were evaluated. Slag aggregate concrete had lesser water penetration depth than the conventional control concrete mix, which is due to the impervious nature of steel slag aggregates. Steel slag is the waste product of steel and iron creating process. Electric arc furnace steel slag has low or no pozzolanic activities and not suitable to be utilized in blended cement manufacture [5].

Advantages of Blast-Furnace Slag Cement includes that, firstly the initial strength achieved is lesser than that of conventional concrete, but at a later period, the strength gained is equal and sometimes higher than conventional concrete. As the slag is grounded finely, it has the capacity to fill the pores efficiently. Workability is high and bleeding is low.

It has good resistance towards sulphate and chloride attack and even less risk of alkali-silica reaction with aggregates. Due to the slow hydration process, the slump retention and initial setting time are more. It has greater durability and reduced permeability due to fineness.

A disadvantage of Blast-Furnace Slag Cement includes, Initial Strength is low, and due to this it cannot be used in RCC works. Also as the initial setting time is high, this cement is not used for emergency or repair works.

The advantages of steel slag include that, it has Greater Hardness, Better Adhesion \& Greater stability, and reduced wear. The disadvantages of steel slag are that of more amount of steel slag affects the environment \& Difficult for disposal. [3]

The chemical constituent of steel slag differs with furnace type, a grade of steel, and a pre-treatment process. The steel slag mainly consists of $\mathrm{SiO}_{2}, \mathrm{CaO}, \mathrm{Fe}_{2} \mathrm{O}_{3}, \mathrm{Al}_{2} \mathrm{O}_{3}, \mathrm{MgO}$, and $\mathrm{MnO}$. The main chemical constituent of blast furnace slag is $\mathrm{CaO}$ which is $56.10 \%$. [1]

If the potential of concrete with regards to strength and durability is to be fully realized, it is most essential that it should be cured adequately. The curing becomes even more important if the concrete contains supplementary cementing materials such as fly ash, or ground granulated blast-furnace slag or silica fume and is subjected to hot and dry environments immediately after casting"'[17].

Concrete containing GGBFS develops strength over a longer period, leading to reduced permeability and better durability. Since the unit volume of Portland cement is reduced, this concrete is less vulnerable to alkali-silica and sulfate attack. Concrete made with GGBFS shows better performance than conventional concrete in chloride-rich environments. As far as cost is concerned, the cost of GGBS in the market including packaging and transporting is three times less than that of OPC.

Laboratory conditions, with strict control of all concrete materials, the slump is generally found to increase proportionally with the water content of a given concrete mixture, and thus to be inversely related to concrete strength. The slump decreases as the substitution rate level of steel slag increases [5]. Granulated blast furnace slag increase in slump value was noticed while the replacement ratio increased. Furthermore, it has been stated that the compressive strength of each concrete decreases as a result of an increase in water-cementitious material ratio.

An exact expectation of tensile strength of concrete will assist in reducing cracking problems, enhance shear strength forecast, and minimize the failure of concrete in tension. Flexural strength is a measure to resist failure in the bending of an unreinforced concrete beam or slab [2].

\section{Materials and Methods}

\subsection{Materials}

The materials used in this study are Cement; fine aggregate, coarse aggregates, steel slag, GGBFS \& potable water. With the help above materials, the concrete of grade $\mathrm{C}-25$ is prepared by varying the proportions of blast furnace slag by keeping $30 \%$ of steel slag in each sample.

\subsection{Methods}

An independent mix of GGBFS and steel slag is investigated. In the investigation, steel slag is added in a $10 \%$ interval up to $40 \%$ and the optimal result is at $30 \%$ and after that, at $40 \%$ the results declined. Therefore an optimal 
percentage of steel slag of $30 \%$ is used in this experimental investigation. The cement is replaced with blast furnace slag up to $30 \%$ with $5 \%$ increment level. The control mix is produced by mixing cement, sand, coarse aggregate, and portable water without the addition of steel slag and blast furnace slag. For example in the case of studying the effect of $30 \%$ steel slag, $25 \%$ of blast furnace slag on the compressive and tensile strength of concrete, cement $(75 \%)$ and blast furnace $\operatorname{slag}(25 \%)$ is added at the same time, fine aggregate $(70 \%)$ and steel slag $(30 \%)$ is added in addition to coarse aggregate. This procedure is similarly repeated for $0 \%$ - 30\% replacement of blast furnace slag by replacing sand with $30 \%$ steel slag in each sample different percentage of GGBFS is added for one constant proportion of steel slag. The steel slag is used as a partial replacement of sand and blast furnace slag as a partial replacement of cement. Then Analysis of materials used for the blast furnace slag and steel slag is done following the investigation of Mix design of blast furnace slag and steel slag to produce eco-concrete. 7 th day and 28th day compressive, tensile, and flexural strength test would have been taken to evaluate the hardened properties of concrete.

174 specimens were cast within which 42 of them is for a tensile strength test, 42 for flexural strength test, and the rest for 90 compressive strength tests.

Preparation of Specimens: Concrete grade used in the investigation is C-25. Firstly the coarse aggregate is added with some water and allowed to mix. Then sand and cement were added and allowed to mix with the coarse aggregate by adding the remaining water.

The mixer thoroughly mixes the concrete to get the appropriate uniformity, and then the slump test is taken in each fresh mix to check the workability of the concrete.

\section{Results and Discussion}

\section{Silt content of sand}

Silt content of the sand is tested by using the jar test and the test result is $4.54 \%$. The maximum silt content recommended by the Ethiopian building Code standard (EBCS) is 6\%. In this test the sand is acceptable.

Particle Size Distribution of blast furnace slag

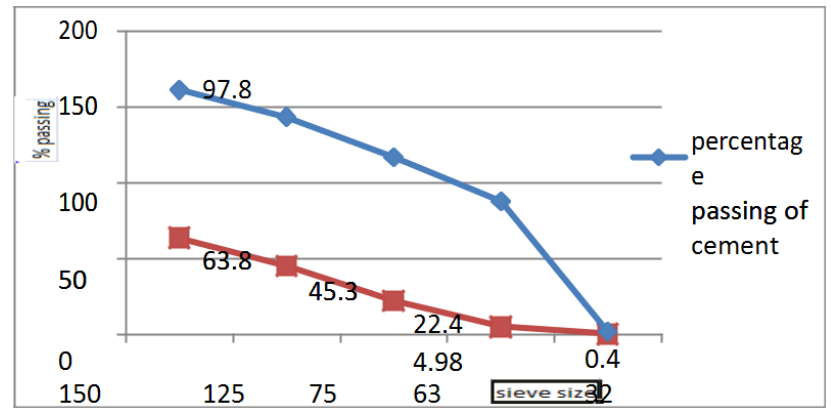

Figure 1. Particle size distribution of $G G B F S$.

Chemical property test of ground granulated blast furnace slag
Complete silicate analysis test

Table 1. Complete silicate analysis of GGBFS.

\begin{tabular}{ll}
\hline Component & Granulated blast furnace slag \\
\hline $\mathrm{SiO}_{2}$ & 25.12 \\
$\mathrm{Al}_{2} \mathrm{O}_{3}$ & 12.82 \\
$\mathrm{Fe}_{2} \mathrm{O}_{3}$ & 27 \\
$\mathrm{CaO}$ & 15.76 \\
$\mathrm{MgO}$ & 13.8 \\
$\mathrm{~K}_{2} \mathrm{O}$ & 1.28 \\
$\mathrm{Na}_{2} \mathrm{O}$ & 0.68 \\
$\mathrm{TiO}_{2}$ & 0.23 \\
$\mathrm{MnO}_{\mathrm{LOI}}$ & 3.6 \\
$\mathrm{P}_{2} \mathrm{O}_{5}$ & $<0.01$ \\
$\mathrm{H}_{2} \mathrm{O}$ & 0.11 \\
\hline
\end{tabular}

It can be seen that the combination of known major oxides i.e. silicon dioxide, Aluminum oxide, Ferric oxide, and Calcium oxide is $80.7 \%$.

\section{XRD Analysis}

XRD test was taken to identify the phase of the GGBFS. The phases could be crystalline or amorphous. crystalline is inactive and does not have cementitious property whereas amorphous has a cementitious property and thus it can be used as a replacement of cement.

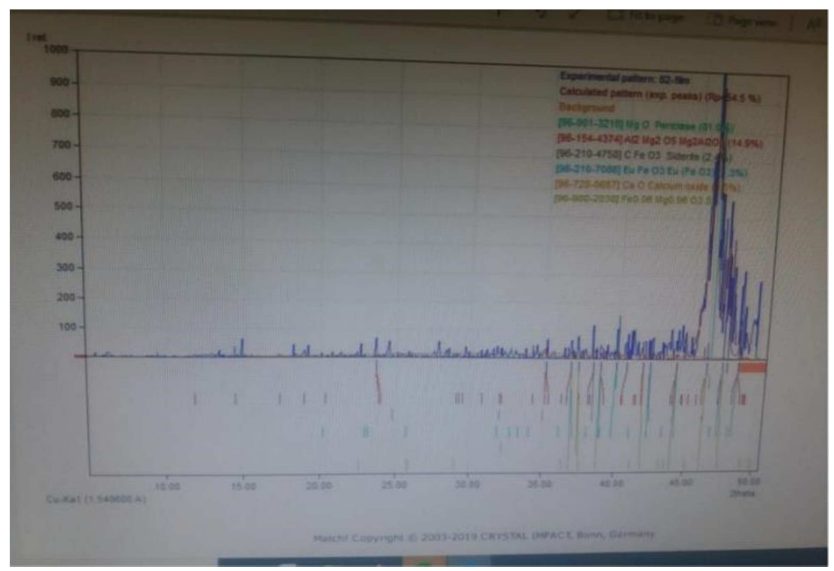

Figure 2. XRD analysis.

Fresh and Hardened Properties of Concrete

Fresh property of concrete

Slump test - It is used to determine the workability of fresh concrete

Table 2. Slump test result for C-25 concrete.

\begin{tabular}{lll}
\hline Sample number & GGBS content & Slump in $\mathbf{~ m m}$ \\
\hline 1 & $0 \%$ & 80 \\
2 & $5 \%$ & 84 \\
3 & $10 \%$ & 86 \\
4 & $15 \%$ & 83 \\
5 & $20 \%$ & 81 \\
6 & $25 \%$ & 79 \\
7 & $30 \%$ & 74 \\
\hline
\end{tabular}

The slump decreases as the percentage replacement of 
GGBFS increases above $15 \%$. The reason behind this is the fineness and particle shape of GGBFS.

Consistency test of the GGBFS

This testing method is investigated to find out the initial setting time, final setting time of the concrete.

Table 3. Consistency test results.

\begin{tabular}{lll}
\hline \%replacement of & Initial setting time & Final setting time \\
\hline GGBFS & (min.) & (min.) \\
\hline $0 \%$ & 160 & 240 \\
$5 \%$ & 151 & 238 \\
$10 \%$ & 134 & 227 \\
$15 \%$ & 120 & 224 \\
$20 \%$ & 118 & 211 \\
$25 \%$ & 114 & 208 \\
$30 \%$ & 101 & 205 \\
\hline
\end{tabular}

Harden property of concrete

Individual Compressive strength test for GGBFS and steel slag

Table 4. Average Compressive test results of 7 and 28 days for steel slag.

\begin{tabular}{lll}
\hline \% replacement of & & Compressive Strength \\
\hline steel slag & 7 Day & 28 Day \\
\hline $10 \%$ & 15.1 & 25.34 \\
$20 \%$ & 16.01 & 26.51 \\
$30 \%$ & 19.46 & 32.72 \\
$40 \%$ & 16.35 & 27.22 \\
\hline
\end{tabular}

As shown in the table, in both the $7^{\text {th }}$ and $28^{\text {th }}$-day compressive strength test, the compressive strength increases gradually up to $30 \%$ replacement. But at $40 \%$ replacement of the sand with steel slag the strength dramatically declines.

Table 5. Average compressive test results of 7 and 28 days for GGBFS.

\begin{tabular}{lll}
\hline \% of blast furnace slag & & Compressive Strength \\
\hline & 7 Day & 28 Day \\
\hline $0 \%$ & 15.55 & 25.83 \\
$10 \%$ & 15.66 & 26.1 \\
$20 \%$ & 15.39 & 25.78 \\
$30 \%$ & 15.01 & 25.01 \\
\hline
\end{tabular}

As shown in the table above, both the 7th and 28th-day test results don't show any big difference between them. Therefore to proceed with the experimental work which has given the most optimal result from the investigation, I choose a $30 \%$ replacement of the steel slag. Then for each replacement of the steel slag, ground granulated blast furnace slag is added in a $5 \%$ difference starting from $0 \%$ up to $30 \%$.

Compressive strength test results of combined GGBFS \& $30 \%$ steel slag

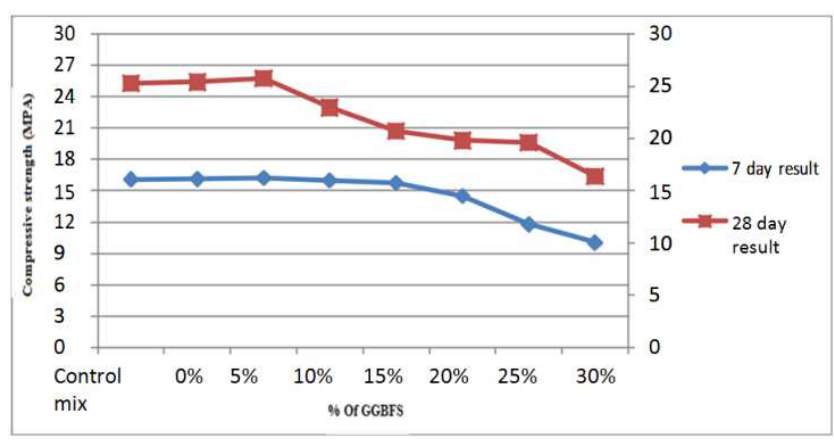

Figure 3. Compressive strength test result.

Compared to the control mix, 5\% replacement of GGBFS has higher compressive strength but the strength decreases as the replacement exceeds $5 \%$.

Splitting tensile strength test results of combined GGBFS \& $30 \%$ steel slag

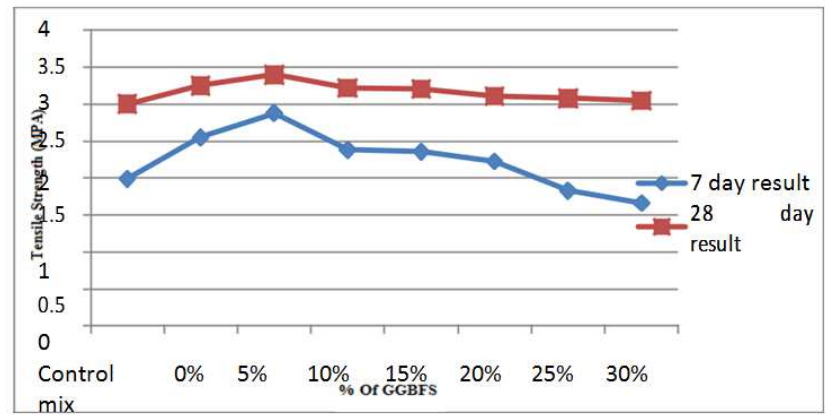

Figure 4. Tensile strength test result.

Values from the above table indicate that the tensile strength of concrete increases as the percentage of blast furnace slag is increased by up to $5 \%$. Above this limit, the tensile strength of concrete decreases.

Flexure strength test results of combined GGBFS \& $30 \%$ steel slag

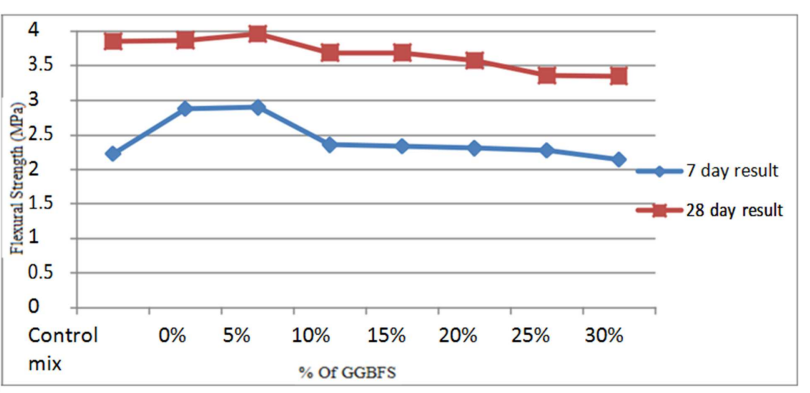

Figure 5. Flexural strength test result (Mpa).

Flexural strength increases up to $5 \%$ replacement of GGBFS. Beyond this proportion, its decline.

SEM

The SEM analysis was done for the raw blast furnace slag and each percentage replacement of $0 \%, 5 \%, 10 \%, 15 \%$, $20 \%, 25 \%$ and $30 \%$.

SEM analyses were performed to examine the interfacial zone between the cement paste and both types of aggregates, dolomite, and slag. 


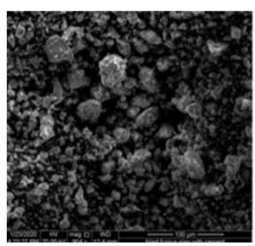

a

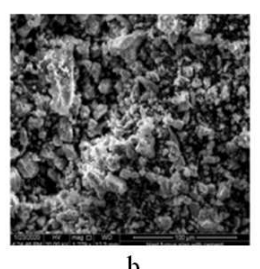

b

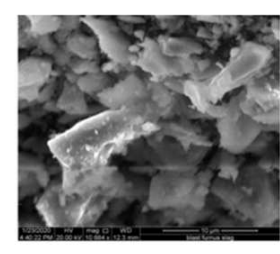

$\mathrm{c}$
Figure 6. A. Raw GGBFS; B. 5\% of GGBFS; C. $30 \%$ of GGBFS

The main parameter for characterizing cement concrete is pore connectivity, which was the highest in a sample of $0 \%$ \& 5\% GGBFS replacement. As shown in Figure 6A\&5B, a very dense microstructure of the hydrated paste in the cement sample can be observed, which guarantees the high compressive strength of cement. But as the replacement of GGBFS increases, the microstructure of the slag shows somehow spherical in shape. This is due to the added slag that has left the pores unfilled. Therefore Compressive strength test result for $30 \%$ replacement shows sudden decrement in strength.

\section{Conclusion and Recommendation}

\subsection{Conclusion}

1) From the experimental results, it is concluded that the percentage replacement of steel slag is $30 \%$ and ground granulated blast furnace slag is $5 \%$.

2) As the curing time increases, the percentage reduction of compressive strength of the concrete decreases which shows that GGBFS affects hydration reaction. Due to the addition of ground granulated blast furnace slag, the hydration process takes a long time and retards the setting time so much. However, it does not affect the initial and final setting time.

3) More total porosity is seen in higher percentage replacement of GGBFS compared to the lower one. A higher proportion of coarse fraction in mixtures results in greater overall porosity. The interlocking effect of GGBFS is noticed because the cement paste penetrated the open porosity of the slag aggregate as the replacement percentage decreases.

4) From the experiment demonstrated for $10 \%, 20 \%, 30 \%$, and $40 \%$ replacement, the strength increases as compared to $0 \%$ replacement.

\subsection{Recommendation}

\section{Recommendation for this study}

1) If $30 \%$ of sand is replaced by steel slag, then ground granulated blast furnace slag replacement for cement should have been $5 \%$. Above this proportion compressive, splitting tensile and flexural strength of concrete will decrease.

2) A mechanism should be set up, and laboratory tests have been conducted which will enforce the use of aggregate of good gradation depending on their type and size since it affects porosity of the concrete which in turn contributes to the higher mechanical strength of the concrete.

3) The mechanism should be set up, which will make intending contractors use concrete made of waste materials and aggregates of good gradation.

4) Site conditions and concrete materials handling on site must be done strictly in compliance with laboratory results and specifications so that the desired quality structure can be constructed.

5) True slump should have been taken at each mix.

Recommendation for future study

1) Research should be carried out on the possibility of producing a machine capable of washing sand locally, to make the use of industrial waste materials more convenient in concrete production.

2) Uneven quality is a problem that plagues slag, as well as all other recycled aggregates whose possibility of application in the particular area of civil engineering has been scientifically proven, which interferes with their use in practice.

\section{References}

[1] Dash, M. K., Patro, S. K. \& Rath, A. K. - A review. Sustainable use of Ind. as Partial Replace. fine Aggreg. Prep. Concr. 5, 484-516 (2016).

[2] Shetty, M.. concrete technology. (2009).

[3] B. Kaviya. R, Arjun, R. Study on Partial Replacement of Cement By Ground Granulated. Int. J. Pure Appl. Math. 116, 411-416 (2017).

[4] M, A. \& MARIA, S. Eco-friendly concrete with rise husk ash. Int. J. Appl. engineering Res. 9, 5471-5489 (2014).

[5] Kadam, P. L. et al. of concrete. 7, 1534-1537 (2016).

[6] Wang, P. et al. Test Study on Cube Compressive Strength of Recycled Lightweight Aggregate Concrete. 630-634 (2016) doi:10.2991/ame-16.2016.105.

[7] Liu, J. \& Wang, D. Application of Ground Granulate Blast Furnace Slag-Steel Slag Composite Binder in a Massive Concrete Structure under Severe Sulphate Attack. Adv. Mater. Sci. Eng. 2017, (2017).

[8] Tamboli, professor M. A.. compressive strength of steel slag and artificial sand in concrete. 6, 0976-6316 (2015).

[9] Rajan, S. study on strength properties of concrete by partial replacement of sand by steel slag. IJETS ISSN01, 2349-3948 (2014).

[10] P. S, K. \& DR. r. Malathy. Utilization of steel slag in concrete as a partial replacement material for fine aggregates. $3,(2014)$.

[11] Seo, M.., Kim, T., G. Hong \& H. Kim. on-site measurements of $\mathrm{CO}_{2}$ emissions during the construction phase of a building complex. (2016)

[12] J. Lizarazo-marriaga. effect of steel slag and portland cement in the rate of hydration and strength of blast furnace slag pastes. 23, (2011). 
[13] Netinger Grubeša, I., Barišic, I., Fucic, A. \& Bansode, S. S. Characteristics and uses of steel slag in building construction. Characteristics and Uses of Steel Slag in Building Construction (2016). doi:10.1016/c2014-0-03994-9.

[14] F. Moody, M. structural biology using electrons and x-rays, 341-347 (2011).

[15] Zhou, W., Apkarian, R., Wang, Z. L. \& Joy, D. Fundamentals of scanning electron microscopy (SEM). Scanning Microsc. Nanotechnol. Tech. Appl. 1-40 (2007) doi: 10.1007/978-0387-39620-0 1.

[16] Arjun, S., Hemalatha, T. \& Rajasekaran, C. Partial replacement of steel slag aggregates in concrete as fine aggregates (induction blast furnace slag). Lecture Notes in Civil Engineering vol. 25 (Springer Singapore, 2019).

[17] Duran Atiş, C. \& Bilim, C. Wet and dry-cured compressive strength of concrete containing ground granulated blastfurnace slag. Build. Environ. 42, 3060-3065 (2007).

[18] S. V. B Reddy, Dr. P. Srinivasa Experimental Studies on compressive strength of ternary blended concretes at different levels of micro silica and GGBFS (2016).

[19] AA, R. \& Vm, M. effect of Curing on the compressive strength, resistance to Chloride-ion penetration and porosity of concretes incorporating slag, fly ash or silica fume cement and concrete composites. 17, 33-125 (1995).

[20] J. Bensted \& P. Barnes. structure and performance of cement. CRC Press2, (2001).
[21] Huang, X., Wang, Z., Liu, Y., Hu, W. \& Ni, W. On the use of blast furnace slag and steel slag in the preparation of green artificial reef concrete. Constr. Build. Mater. 112, 241-246 (2016).

[22] G. I, G. et al. scanning electron microscopy, and x-ray microanalysis. ISBN (1981).

[23] Y. Liu, H. Fang \& L. Lu. research progress on the techniques of treatment and comprehensive utilization of steel slag. Chem. eng.equip. 09 190-192 (2014).

[24] M. S. Shetty. concrete technology theory and practice. (2005).

[25] Dave, N., Misra, A. K., Srivastava, A. \& Kaushik, S. K. Setting time and standard consistency of quaternary binders: The influence of cementitious material addition and mixing. Int. J. Sustain. Built Environ. 6, 30-36 (2017).

[26] D. Breton. contribution to the formation mechanism of the transition zone between rock-cement paste and cement concrete. 23, 335-346 (1993).

[27] M. S. Imbabi, C. Carrigan, S. McKenna, Trends and development in green cement and concrete technology, Int. J. Sustain. Built Environ. 1, 194 (2012).

[28] E. Yogarajah, T. Nawa, T. Igarashi, Physical, chemical, and mineralogical characteristics of blast furnace slag on the durability of concrete. 060-8628 (2018).

[29] B. A. Zulu, S. Miyazawa, and N. Nito 3 Properties of BlastFurnace Slag Cement Concrete Subjected to Accelerated Curing 31 October (2019). 